UC- 420,426

THE EFFECT OF INTTERNAL MAGNETIC STRUCTURE ON THE FISHBONE INSTABILITY

BY

D.W. ROBERTS, R. KAITA, F. LEVINTON, ET AL

January 1992

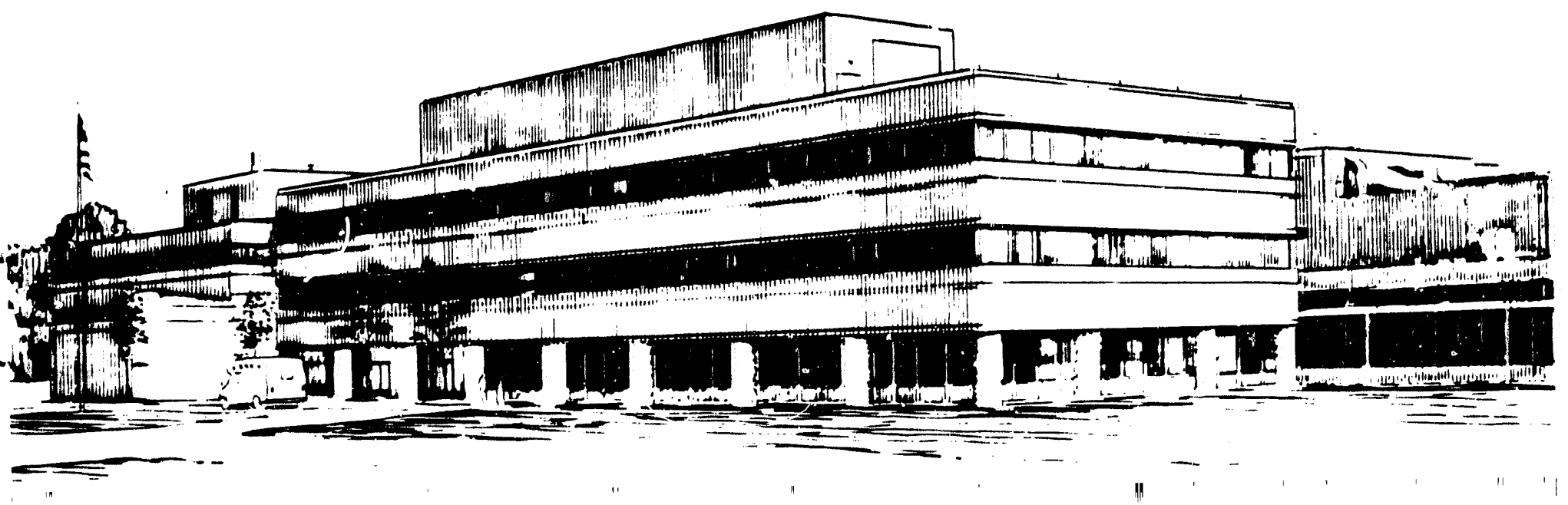




\section{NOTICE}

This report was prepared as an account of work sponsored by an agency of the United States Government. Neither the United States Government nor any agency thereof, nor any of their employees, makes any warranty, express or implied, or assumes any legal liability or responsibility for the accuracy, completeness, or usefulness of any information, apparatus, product, or process disclosed, or represents that its use would not infringe privately owned rights. Feference herein to any specific commercial produce, process, or senvice by trade name, trademank, manufacturer, or othenwise, does not necessarily constitute or imply its endorsement, recommendation, or favoring by: the United States Government or any agency thereof. The views and opinions of authors expressed herein do not necessarily state or reflect those of the United States Government or any agency thereot.

\section{NOTICE}

This report has been reproduced directly from the best available copy.

Available to DOE and DOE contractors from the:

Office of Scientific and Technical Information

P.O. Box 62

Oak Pidge, TN 37831 ;

Prices available from (615) 576-8401.

Available to the public from the:

National Technical Information Service

U.S. Department of Commerce

5285 Port Royal Road

Springtield, Virginia 22161

$703-487-4650$ 


\title{
The effect of internal magnetic structure on the fishbone
}

\section{instability}

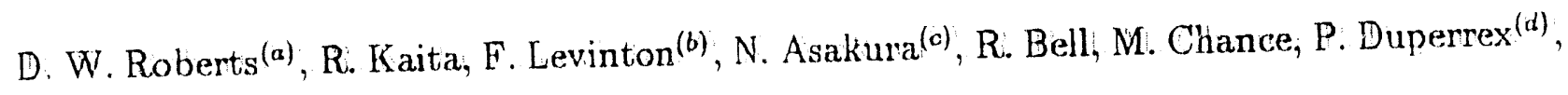
G. Gammel ${ }^{(e)}$, R. Hatcher, A. Holland, S. Kaye, C. Kessel, H. Kugel, B. LeBlanc, J. Manickam, M. Okabayashi, S. Paul, N. Pomphrey, E. Powell ${ }^{(a)}$, N. Sauthoff, S. Sesnic, H. Takahashi, R. White Princeton University Plasma Physics Laboratory, Princeton, N.J.

\begin{abstract}
Plasmas exhibiting the "fishbone" instability studied on the PBX-M tokamak show a distinct relationship between the plasma shape, the internal magnetic structure, and the presence or absence of fast ion losses normally associated with the fishbone mode. We. have, for the first time, carried out measurements of the magnetic safety factor profile in fishbone-unstable plasmas, and used the knowledge of the associated experimental equilibria to compare the stability and fast ion loss properties of these plasmas with experimental observations.
\end{abstract}


The use of auxiliary heating to achieve high temperatures in tokamak plasmas thas led to the observation of a class of instabilities not fully described by simple magnetohydrodynamic (MHDD) fluid theory," where kinetic effects associated with the high enengy particles in the plasma play an essential role. One such instability is the "fishbone" mode, which was first observed on the PDX tokamak ${ }^{2}$ during high power, near-perpendicular neutral beam injection (NBI). The lange-amplitude MFDD fluctuations characteristic of the mode were associated with greatly enhanced losses of the energetic beam ions near the NBI energy, degrading the efficiency of plasma heating and limiting the attainable $\beta\left(=\frac{\langle p\rangle}{B^{2} / 8 \pi}\right)$ values. $^{3}$ The MHD activity indicated that the polbidal and toroidal mode structure of the instability is $m / n=1 / 1$ in the plasma core, with a spectrum of modes with $m \geq 2$ nearer the plasma edge. The modes rotate toroidally at approximatiely the precession rate of the trapped beam ions.

Fishbones have been attributed to a resonance between a population of high enengy, toroidally precessing ions and an unstable (or marginally stable) internal kink mode, ${ }^{4-7}$ or alternatively, a coupling of the hot ions, through viscous damping in the bulk plasma, to an MHD mode at the ion diamagnetic drift frequency of the thermal ions. ${ }^{8}$ The relatively cold background plasma is described by an MHD model. The stability analysis is done via the energy principle. ${ }^{1}$ The procedure is to add to the contribution of $\delta W_{M H D}$ from the background plasma terms due to the kinetic, $\delta W_{k}$, and inertial, $\delta_{I}$, terms, leading to a variational dispersion relation, ${ }^{\top}$

$$
D(\xi)=\delta W_{M H D}+\delta W_{k}+\delta_{l}=0 .
$$


In this dispersion relation, the inertial tem resolves the singularity in the displacement $\boldsymbol{\xi}(\mathbf{r})$ at the $q\left(r_{s}\right)=m / n=1$ rational surface, and its contribution is important only. in this vicinity. The kinetic term arises from the hot trapped particle population. The size of this population is characterized by the hot particle beta, $\beta_{h}$. For even modest values of $\beta_{h}\left(\sim 10^{-3}\right)$, the $\delta W_{k}$ tenm can destabilize a marginally stable internal kink mode $\left(\delta W_{M H D} \gtrsim 0\right)$. The resulting mode has a frequency $\omega \sim \omega_{d}$, where $\omega_{d}$ is the toroidal precession frequency of the hot trapped panticles, $\omega_{d d} \sim E_{i n j} q / m r R \Omega$. Such a mode is observed experimentally. ${ }^{9}$

The onset conditions for the fishbone mode have been calculated for a slowing-down distribution of hot particles produced by NBI. The threshold condition corresponding to the fishbone modes observed on PDX, PBX, and PBX-M is found to be

$$
\beta_{c r i t, h}=\frac{\left\langle\omega_{d t}\right\rangle}{\pi \omega_{A}}
$$

where

$$
\omega_{A}=\frac{v_{A}}{\sqrt{3} R r_{s} q^{\prime}}
$$

is the shear Alfvén frequency evaluated at $q\left(r_{s}\right)=1$, and $r_{s} q^{\prime}$ is the magnetic shear at the rational surface. ${ }^{10}$

Part of the dependence of the instability on the safety factor $q$ can be seen clearly from the expressions for $\left\langle\omega_{t d}\right\rangle, \omega_{A}$, and $\beta_{c r i t, h}$. In addition, the mode structure depends on the radial location of the rational surfaces; a measurement of $q(r)$ would provide important confirmation of the mode/hot-ion resonance model. To date, such meatsurements 
have not been made routinely and have never been made in plasmas exhibiting fishbones. Using the neutral probe beam $q$ profile diagnostic available on PBX-M, we have obtained the necessary information to compute a plasma equilibrium that accurately models the experiment. We can use this to determine the plasma's stability, and study the predicted. dependence of mode/hot-ion resonances such as those associated with the fishbone in stability. This paper describes experiments in which the fishbone mode was excited and measured on PBX-M and $q$ profile and fast ion measurements were made. These experiments provide the first companison between the theoretically predicted dependence of the mode on the internal magnetic structure of the plasma and actual experimental measurements of $q(r)$ made by using motional Stank effect polarimetry. ${ }^{1.19}$

The fishbone experiments were conducted in low field, low cument, bean-shaped plasmas. At $400 \mathrm{~ms}$ into the dischange, the plasma shape relaxed from a bean-shaped condition, with elongated internal flux surfaces, to a more D-shaped condition, with relatively circular internal surfaces. At the time of the relaxation, the amplitude of the fast ion losses-as seen by a perpendicularly viewing, multichannel, charge exchange analyzer (FIDE) $)^{12}$-increased sharply. Figure 1 shows the Mirnov loop signal from a coil on the outboard midplane and the fast ion signal seen by the FIDE analyzer near the NBI energy for the earlier bean-shaped, fast ion loss-free phase. Coherent fishbone oscillations are clearly seen on the Mirnov trace, but we see no evidence of fast ion losses associated with these fishboness.

Figure 2, similar to Fig. L, shows the signal from the midplane Mirnov loop and the 
perpendiculan fast ion losses seen by the FIDE analyzen during the laten D-shaped, fast ion loss phase. As in the early, fast ion loss-free phase, colienent fishbone oscillations ane clearly seen on the Mirnov trace. However, there are now also coherent burstis of fast ion losses associated with the fishbones. The similanity in the Mirnov data and in the basic plasma conditions (llow density, high- $\beta$, high $-\beta_{p}$ ) indicates that during both the early and late phases, conditions are such that an MIFD fishbone mode is destabilized; howeven, differences in the plasma equilibrium have developed during the relaxation at $t=400 \mathrm{~ms}$ causing the observed change in the fast ion loss behavion.

To detemine the $q(r)$ profile during each phase, two magnetic field pitch angle $\left(\gamma_{p}\right)$ measurements were made with the motional Stark effect (MSE) polanimeter. ${ }^{13}$ The $q(\psi)$ and $q(r)$ profiles obtained from the $\gamma_{p}$ data $^{14}$ for the early (fast ion loss-free) phase and the late phase are shown in Fig. 3. Comparing these results, we begin to see the changes in the equilibrium that we believe are responsible for the differences in the observed fast ion losses. At the late time, the $q(r)$ [and $q(\psi)]$ profile becomes broader. In particular, the radius of the $q=1$ surface increases. The $q(\psi)$ profile shows this more clearly, since the motion of the magnetic axis $R_{0}$ is suppressed by the use of the flux $\psi$ as the independent, variable:.

During the course of our studies, several plasma discharges were observed that showed considerably enhanced fast ion losses during the late pliase of the discharge. The strength of these losses increased by roughly a factor of five over the previously described losses: The Mirnov data suggest that, for these enhanced loss cases, a similar mode/hot-ion 
resonance is present in the cone, but again the details of the equilibrium determine the degnee of fast ions losbes: To understand this, the MSE $\gamma_{p}((n))$ datia were used in an equilitbrium reconstruction for one of the enthanced loss shotis: The $q((\psi))$ and $q((r))$ profiles: for the enhanced lbss case are substantially: broaden anai mone Uhshaped than in the conventional late case. This observation is consistent with the diffenence in the $q$ / profile between the conventional, fast ion loss-fwee eanly phase and the fast ion loss late phase: The observations indicate that the $q$ profile broadens and flatitens, and as the radius: of the $q=1$ surface increases, the strength of the fast ion losses associatied with the fishbones rises accondingly:

We compared these results with the fast ion losses predictied by the Whitie-Chen fishr bone model by using the guiding center code ondun, developed by White and Chance: ${ }^{15}$ The code studies the fast ion losses resulting from a penturtbation of the axisymmetric equilibrium magnetic field due to the MHD modes of the mode/hot-ion resonance: Previous fast ion loss studies employing on Bur have used analytic equilibria, on numerical equilibria in which one or mone of the quantities $p(\psi)$, $q(\psi)$, on $g(\psi)$ had an assumed analytic form. ${ }^{4,15}$ With the magnetic pitch angle data from our fishbone experiments and the resulting equilibrium reconstructions they provide, we have for the finst time companed the prextictions of the White-Chen model for fast ion losses with tha observed losses and accirrate equilibrium information in each of our experimental conditions.

The fast ion loss calculations made by uning on tan vequine the equilibrium informat tion discusserd above as well as amplitudes of each polbidal and toroidal ( $m, n)$ component 
of the MIHID activity: To obtain the amplitudes of each $((m, n))$ component, we inconpor rated both oun measuned Minnov data and stability: resultis: from the PEs ideall MICHD stability code. ${ }^{16}$ Using pesn, we found that the fast ion loss-fnee phase of the shaped, fishboning plasmas was unstable to the intemal kink. From this analysis, we determined the maximum amplitude of each $((m, n))$ mode measured at the plasma edge: Fon the latie; fasti ion loss phase of the shaped, fishboning plasmas; we cannied out stability analyses for both the conventionall and enthanced loss cases. The Pes'n nesultis fon each case indicate that the plasmas: wene unstable to the internall kink as in the earlien time. The bnoad, flat q profile in the later cases, howeven, leads to a significantly langen nadiall extient for the internall kink activity.

The predominant MHD modes found by using Pesin and oun Mimov measurements: for the eanly and late phases were quite similan: the basic chanacten of the MUHD activity: seen in the Mirnov data was essentially unchanged by the shape nelaxation at $t=400 \mathrm{~ms}$, the mode analysis of the Mirnov datia showed that the predominant $(m, n)$ contnibutions to the MHDD activity at the early and late times were $m=1, n=1$ and $m=2, n=1$, and the frequencies at the eanly and late times diffened only slightly. Fioweven, the fast. ion behavion for each phase was quite different. These results indicate that the basic Huid stability conditions for driving fishbones exist in the cone at both ohe early and late times.

Betanse the Hind stability for both the fast ion loss-fores phate and the fast fon lons phase were the same, we next examined the kinetic stibility propenties of each time, using 


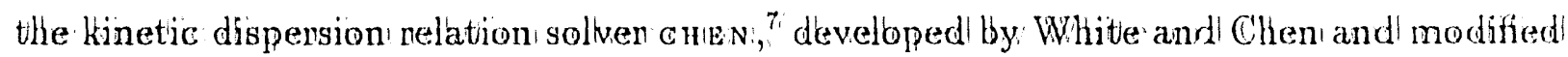
for this work to allow: more accurate neconsturuction of the expenimentally: detemmined q profile: Each of our cases was: found to be unstable to the fishthone mode acconding to these calculations: The diffenences in measuned fast ion losses: ane thus due neithen to gross diffenences: in MIHD behavion nor in kinetic stability. Rathen, othe relationship' between the intiennal profiles and the fast ion dnifts associatied with the mode must explain the difference in behavion.

To verify this relationship, we usedl oun experimentall equilibria, the measuned neut trall beam panameters, and the MHOID mode amplitudes described above to obtain the calculated fast ion losses with the ortun code. Table I summanizes the observed and calculated mode propenties for the fishbone observations in each of our three cases. The fraction of beam particles that ane trapped is obtained from the or aur calculation. The shear Alfvén frequency, $\omega_{A}$, is found using. Eq. (3) and the equiiibrium resultos for each case. The avenage precession rate for the trapped panticles, $\left\langle\omega_{d}\right\rangle$, , is obtained from on

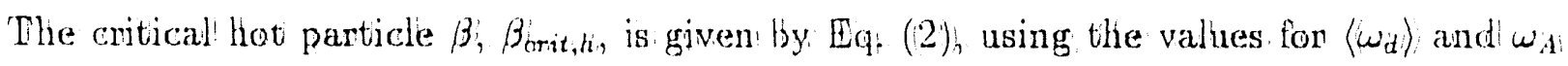
discussed above. Finally, the mode frequency is equall to $\left\langle\omega_{d}\right\rangle / 2 \pi$. The observed and calculated mode frequenties are in agneement. Note that the fistibone threshosld suggestis that the early, fast ion loss-free case is at leant as unstable as the latier times. The fraction of fast ions trapped within the kiak nesonance at $q=1$ seems to confirm the nelationship between q profile shape and observed lowses.

The nesults of our on and calculations for the tast ion losses predicted for eacth of on 
cases ane shown in Fignes 4l. The plots sliow the enengy distribution of exiting panticles: fon the eanly;, latie; and enthanced! loss cases: From the figune; we see that the magnitude: of fast ion losses; in the conventionall late case is albout seven times gpeatien than in the eanly case. This agnees, with our experimentiall observations, whene in the eanly case, we could discenn no fast ion losses above the noise. The magnitude of the fast ion losses fon the enthanced loss case shows an increase of two to thnee over the conventionall latie case: Companing, the nelative amplitude of the losses fon the conventional and enthanced loss: cases, we find that oun results obtained fnom the White-Chen modell substantially/ agnee with the expenimentally obsenved variation in flast ion losses:

We have observed that in plasmas exhibiting the fishthone instability, the detiails of the equilibria-nelated in oun case to the plasma shape and $q /$ profile-can gneatly affect the observed fast ion losses. While oun results suggest that plasmas of different shapes may: not differ in thein stability against fistibone modes, the influence of shape on the details of the equilibriunu profiles can affect the fast ion losses associated! with these fistibones: This can have important implications in the operation of a burning plasma expeniment on a fusion test reacton, in which the loss of hight energy particles, eithen fnom auxiliary: heating on from fusion products themselves, could gpeatly affect the performance of the device. ${ }^{17}$

This work was supported by U.S.DOE Contmats No. DE-AC02-76.CHOBOn3 and DE-ACOB-86-ER80409: One of the anthons (D.R.) has been under appointment to the Magnetc Fusion Science Fellowship program adiministened by Oak Ridge Associated IJni- 
vensities; fon the U.S: Depantment of Dinengy:
(a)) Univensity of Callfomia, Lo wnence Livemone Nationall Labbonationy, Linemone; (CA.
(b)) Fusion Physics and Technology, Torrance; (CA!.
(a)) Univensity: of Tokyo, Trokyoy, Japan.
(d) Ecole polyttechnique fédénale de Lausanne, Lausanne, Switzenland!
(e) Grumman Alenospace Conponation, Bethpage; NY. 


\section{Figures}

FIG. 1. The midplane Mirnov coil and perpendicular fast ion (FI) loss data for tiie fast; ion loss-free phase of the shaped, fishboning plasma case.

FIG. 2. The midplane Mirnov and FI loss data for the late, fast ion loss phase of the shaped, fishboning plasma case. The figure shows a series of fishbone oscillations, including the coherent fast ion losses that appear at the late time.

FIG. 3. A comparison between the $q(\psi)$ and $q(r)$ profiles for the early and late phases of the shaped, fishboning plasmas.

FIG. 4. The energy distribution of the predicted fast ion losses for each of our shaped, fishboning plasma. cases. The magnitude of the losses for each case are in good agreement with the experimental observations. 


\section{Tables}

TABLE I. A summary of the observed and calculated fishbone properties for each phase of our shaped, fishboning plasmas. 


\section{References}

1J. P. Freidberg, Ideal Magnetohydrodynamics, Plenum Press, New York, 1987.

${ }^{2}$ K. McGuire et al., Phys. Rev. Lett. 50, 891 (1983).

${ }^{3}$ D. Johnson et al., in Plasma Physiscs and Controlled Nuclear Fusion Research 1982, (Proc. of the $9^{\text {th }}$ Internat. Conf., Baltimore, 1982), Vol. 1, pp. 9-26, Vienna, 1983, IAEA.

${ }^{4}$ R. B. White et al., Phys. Fluids 26, 2958 (1983).

${ }^{5}$ L. Chen, R. B. White, and M. N. Rosenbluth, Pliys. Rev. Lett. 52, 1122 (1984).

${ }^{6}$ L. Chen et al., in Plasma Physcis and Controlled Nualear Fusion Research 1984, (Proc. of the $10^{\text {th }}$ Internat. Conf., London, 1984), Vol. 2, pp. 59-67, Vienna, 1985, IAEA.

${ }^{7}$ R. B. White, L. Chen, R. Romanelli, and R. Hay, Phys. Fluids 28, 278 (1985).

${ }^{8}$ B. Coppi and F. Porcelli, Phys. Rev. Lett. 57, 2272(1986).

${ }^{9}$ R. Kaita et al., Phys. Fluids B 2, 1584 (1990).

${ }^{10}$ R. B. White, M. N. Bussac, and F. Romanelli, Phys. Rev. Lett. 62, 539 (1989).

${ }^{11}$ F. M. Levinton et al., Phys. Rev. Lett. 63, 2060 (1989).

${ }^{12}$ R. Kaita, R. J. Goldston, D. Meyerhofer, and I. Eridon, Rev. Sci. Instrum. 52, 1795 (1981). 
${ }^{13}$ F. Mi Levinton, G. M. Gammel, R. Kaita, H. W. Kugel, and D. W. Roberts, Rev. Sci. Instrum. 61, 2914 (1990).

${ }^{14}$ D. W. Roberts, R. Kaita, and F. M. Levinton, Rev: Sci. Instrum: 61, 2932 (1990):

${ }^{15}$ R. B. White and M. S. Chance, Phys. Fluids 27, 2455 (1984):

${ }^{16}$ R. C. Grimm, J. M. Greene, and J. L. Johnson, in Methods in Computational Physios, Vol. 16, pp. 253-280, Academic Press, New York, 1976.

${ }^{17}$ H. P. Furth, R. J. Goldston, S. J. Zweben, and D. J. Sigmar, Nucl. Susion 30, 1799 (1990). 


\begin{tabular}{|l|c|c|c|}
\hline Mode characteristics & Early & Late & Enhanced Loss \\
\hline Observed mode frequency $(\mathrm{kHz})$ & $15-25$ & $101-20$ & $10-20$ \\
Fraction of beam trapped $(\%)$ & 64 & 82 & 79 \\
Fraction of beam trapped, $q<1(\%)$ & 8 & 21 & 42 \\
Shear Alfvén, $\omega_{A}\left(\mathrm{sec}^{-1}\right)$ & $3.8 \times 10^{6}$ & $2.6 \times 10^{6}$ & $1.8 \times 10^{\beta}$ \\
Precession rate $\left(\omega_{t d}\right)\left(\mathrm{sec}^{-1}\right)$ & $8.8 \times 10^{4}$ & $9.3 \times 10^{4}$ & $1.0 \times 10^{5}$ \\
Fishbone threshold, $\beta_{h, \text { crit }}$ & $7.4 \times 10^{-3}$ & $1.1 \times 10^{-2}$ & $1.8 \times 10^{-2}$ \\
Calculated mode frequency $(\mathrm{kHz})$ & 14 & 15 & 16 \\
\hline
\end{tabular}




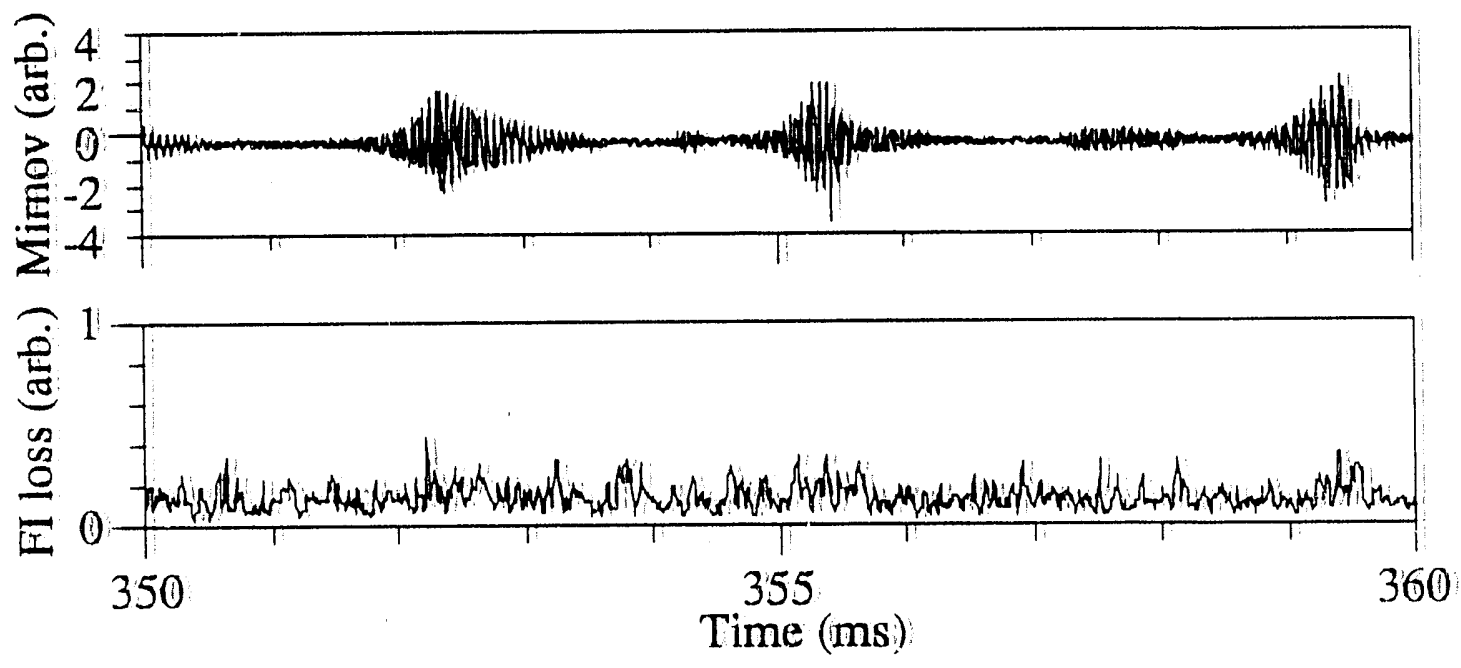

Figure 1. 


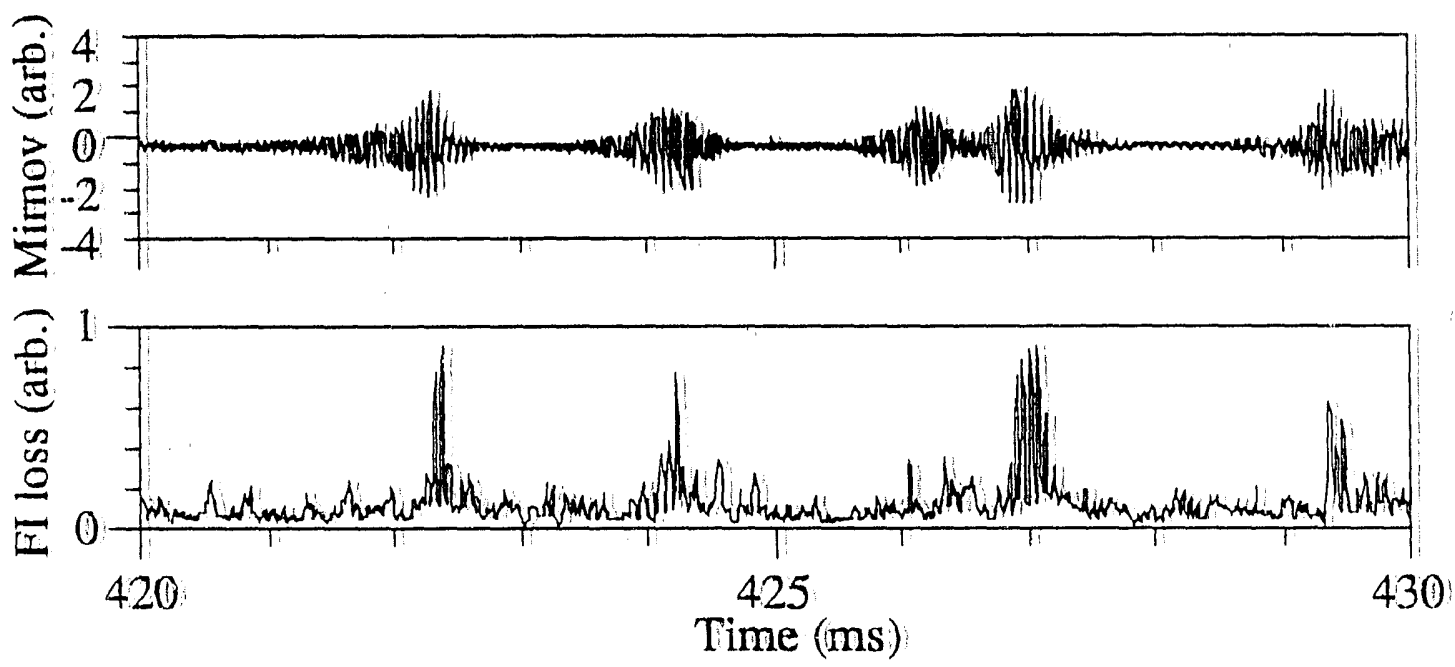

Figure 2. 

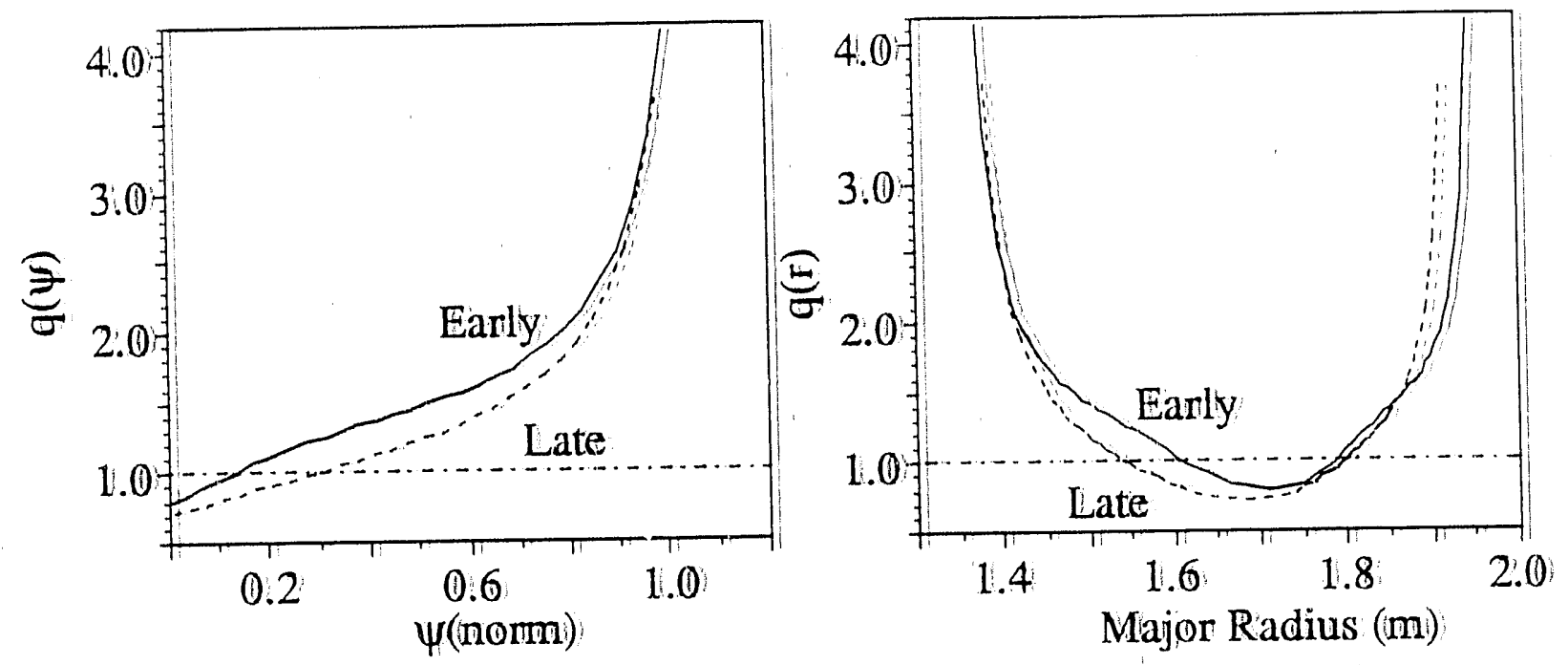

Figure 3. 


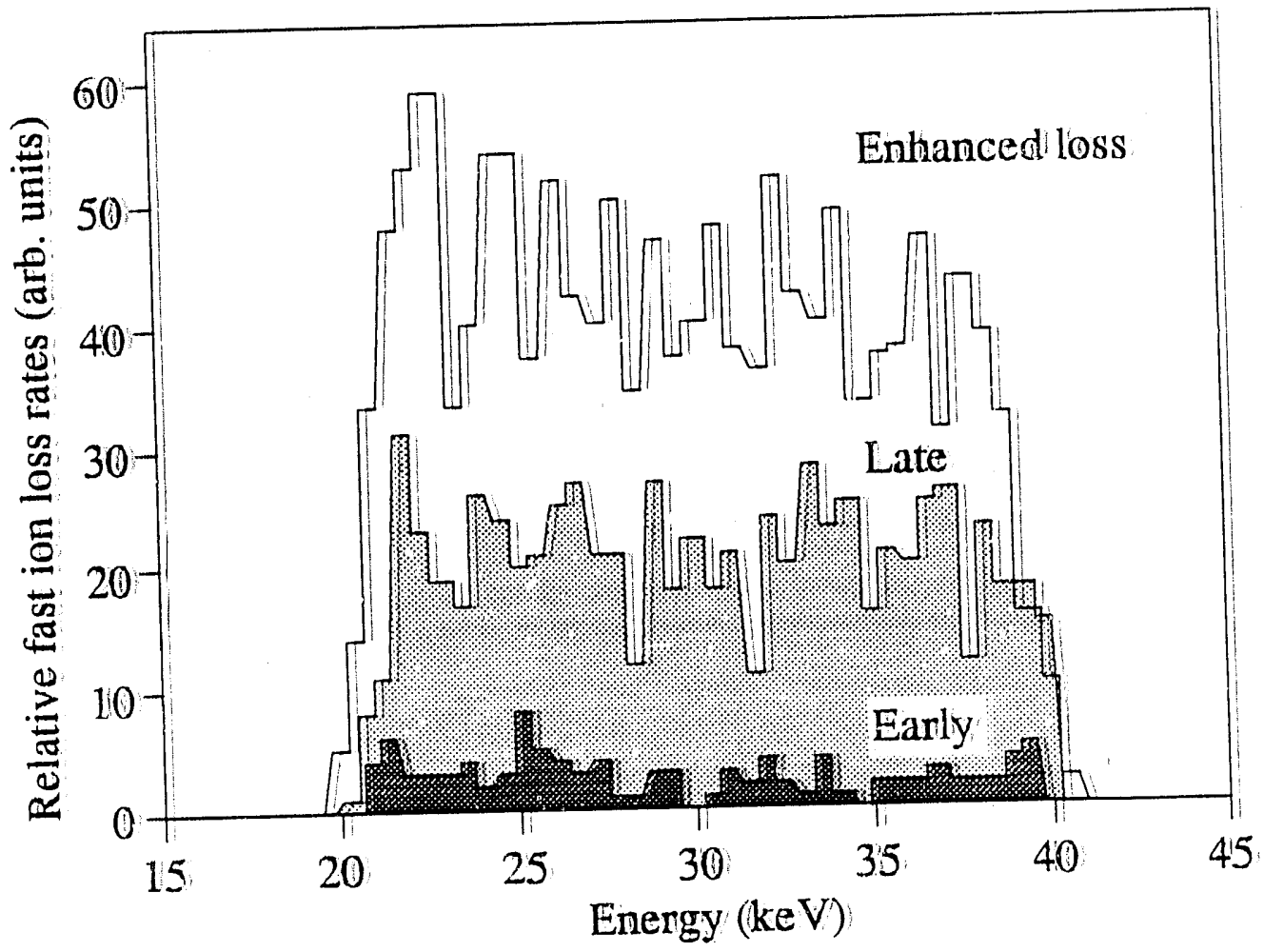

Figure 4. 
Dr: F. Pagolonii Univi af Wollongong, AUSTRALLIA

Profi MiHI Brennan, Univ af ISydhey, AUSTRALLA

Plasma Presearctillabi), Australian Nat Uhivi, AUSTRALUlA.

PrafillR Janes; Filinders Univi, AUSTRALUIA:

Profi F. Cap, Inst for TheoreticallPhysios; AUSTRIA

Praf . M. Heindier, Ihetitutifar, Theoretisctie, PHysik, AUSTRIIA

Prafi M Coossens, Astronomischilhstituut, BELGIUM

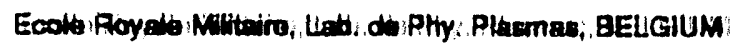

Cammiseion Europeen, DG. XIItFusion Prog, , BELGIUM

Prof A. Bouciqud, Rinkuniwersiteit Cent BELGIUN

Dr. P.4. Sakenaka, Insttuto Fitice, BPAZTL

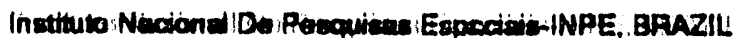

Documents Olfice, Atomic Energy af Canad Lite!, CANADA

Dr. MP. Bactiynsti, MPB Tectinalogios, Ihe., CANADA

Dr. HIM. Skarsgard, Univ of Sadkatctiawen, CANAOA

Profi.J. Teictimann, Univ of Muntreal CANADA.

Proti S.A. Sreenivean;, Univ. of Catgary. CANADA

Prof T:W. Jathoton, INASErinergie, CANADA.

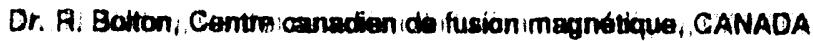

Dr. C.R. James, Univ. of Alberta, CANADA

Dr. P. Luktic, Komenskitho Universzita, GZECHOSLLOVAKIA

The Librarien, Culhem Laboratory, ENGLAND

Librery, A81, Ruthertord Applaton Llaboratory, ENGLANO

Mrs. S.A. Hubeninean, JET Librery, ENGLAND

Dr. S.C. Shama, Univ, af South Pacific, FiUIIISLANDS

P. Mathónen, Umiv. of Holsinki, FINLLAND

Prat. MIN. Bussec, Ecole Polytectinique, , FRANCE

C. Nouttat, Lato de Physique des Mileux lanises, FRANCE

J. Radat, CEN/CADAFACHE - Bat 506, FFANCE

Prot. E. Economou, Univ. af Creto, GREECE

Nas. C. Ainni, Univ. of lammina, GAEEECE

Dr. T. Nurl, Acaderny Bibliograptic Ser., HONG KONG

Preprim Library. Hungarian Acadamy of Sa., HUNGAFY

Dr. B. DasGupta, Saha inst. of Nuctear PPrysics, INUIA

Dr. P. Kaw, Inst. for Plasma Pasuarch, INDIA

Dr. P. Rosenau, Ieraed Inst. of Tectinokigy, ISARAEL.

Litrarian, Intomational Canter for Theo Physics, ITALY

Miss C. De Palo, Associazione EURATOM-ENEA, ITALY

Dr. G. Grasso, Istituto di Firica del Plasma, ITALY

Prof. G. Rostangni, I sthuto Gas lonizzat Del Cnr, ITALY.

Dr. H. Yamata, Toghiba fles \&evel Center, JAPAN
Rrofi II. Kawakami, Hhroshima Uhivi, JAPA AN

Profi. K, Nistiikawa, Hhoshima Uhiv/, JAPAN

Direotor, Japan , Alomic : Energy/Hesearathilhgti, JARANI

Rrofi S: Itohi, KYustiulUhivi, JA:PAN!

Researctilhito, Crr, Nationallingtit for Fusion ISoience, JARANI

Profi.S. Tanaka, Kyoto Uhivi, JAPAN

Library, Kyow Univi, JAPAN

Profi N. Ihoun, Univi of Tokyo, JAPAN

Sucrotery, Plarma Swotion, ElectrotoctinicallLabi, JAPAN!

S: Mori, Toathicad/hodizizor, JAERII, JAPAN

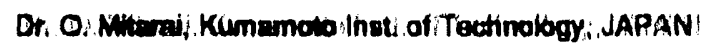

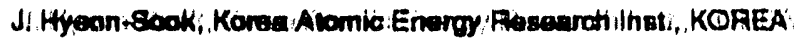

Dill Chai, The Korea Advi Inst af Scoi \& Teati, KOREA

Prof BS: Lilay, Univi of Waikato, INEW/ZESILAND

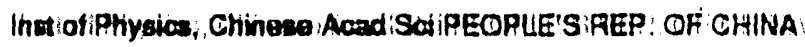

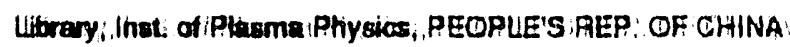

Tringtiua Univ Library, PEOPUES REPUBLIC: OF CHINA

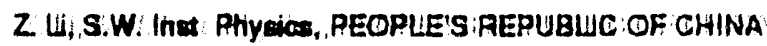

Profi JiA,C. Cabral, Inatituta Suporior Teonico, PORTUGALL

Dr. O. Petrus, All ll Cuza Univi, Romania

Dr. J. do Villers, Fumion Stucties, AEC, S: AFFICA

Prof MiA. Hallberg, Univi of INatal, S. AFFACA

Prot. D.E. Kim, Pohang Inut of Sai \& Techi, SO. KOAEA

Prof. C.IIE.MA.T, Fusion ORvision lubrary, SPAIN

Dr. Li Stonth, Univ of UMEA, SWEDEN

Library, Royed Inst. of Tectinology, SWEDEN

Praf. HI Whitheon, Chaimers Univ: of Tecti, SWEDEN

Centre Phys. Des Placmas, Ecols Polytech, SWITRERLAND

Bibliotheak, Inst. Voor Plasma-Fysica, THE NETHERLANOS

Acot. Prof. Dr. S. Cotir, Nidole Eant Tecti, Univ., TURKEY

Dr. V.A. Gukthikh, Sca. Ros. Inst. Electrophys.: Apparatus, USSA

Dr. D.D. Ayutov, Sibarian Branati of Acendany of Sa, USSA

Dr. G.A. Elieedv, IVV. Kurctiatov/net., USSA

Librarian, The UKr.SSA Academy af Sciances, USSA

Or. LM. Kavriztimykh, Inst. af Generd Physics, USSA

Kemtorsctungeanlage GmbH, Zentralbibliathek, W. GERMANY

Biblikthek, Inst. Für Plesmatorsching, W. GEFMANY.

Prat. K. Scctinder, Ruhr-Universitát Boctium, W. GERManY

Dr. F. Wagner, (ASDEX), Max-Planck-ingtitut, W. GEPMANY,

Librarian, Max-Planck-Institut, W. GERMANY.

Prot. A.K. Janev, Inat. of Physics, YUGOSLAVIA 

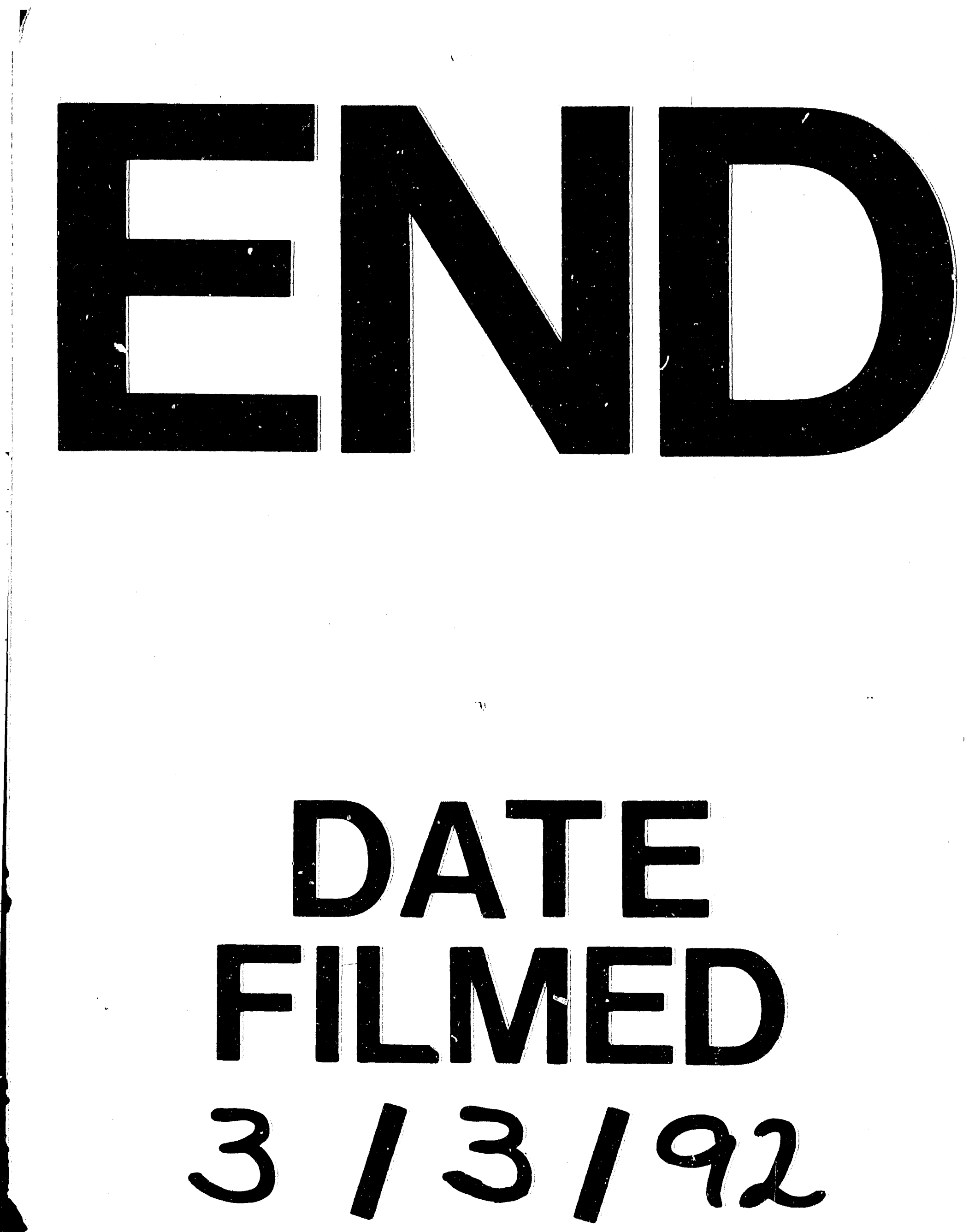
